\title{
Learning From and With Community Organizations to Navigate the Tensions of Democratic Engagement
}

\author{
Brandon Whitney \\ ioby \\ Barbara Harrison \\ Patti H. Clayton \\ PHC Ventures, IUPUI, \& University of North \\ Carolina at Greensboro
}

\author{
Stacey Muse \\ University of Nevada, Reno \\ Kathleen E. Edwards \\ University of North Carolina at Greensboro \& \\ Interactive Resource Center
}

In his 2015 framing essay for the ServiceLearning \& Community Engagement Future Directions Project (SLCE-FDP), Edward Zlotkowski challenges the movement to think carefully about "where we locate the center of our efforts" (p. 84) and reconsiders whether the focus on academic legitimacy and institutional transformation he called for in his 1995 essay "Does Service-Learning Have a Future?" ought still to be the priority 20 years later. $\mathrm{He}$ also commends several of the 2015 SLCE-FDP thought pieces for calling attention to "voices often unrepresented or underrepresented" (p. 84). In this essay, we try to further deepen the role of community members and organizations in the movement's efforts to understand and address the opportunities and challenges of the present and future. Specifically, we call on our campus-based colleagues to seek out and learn from examples of community organizations that, in their day-to-day work, enact the principles of democratic engagement; and we call on our community-based colleagues to share and critique their own efforts. We envision the future of SLCE as bringing to life the commitments of democratic engagement and thereby nurturing shared responsibility for and shared power in nudging the world toward peace and justice. And we believe the SLCE movement as a whole can learn much from what may prove to be more democratic and cutting edge approaches in the broader community than are often found in the academy.

We have first-hand experience as leaders, staff, partners, and volunteers with community organizations that work diligently to achieve democratic ends through democratic means in social and cultural contexts that make doing so difficult. We find in candid examination of two of our organizations' efforts some illumination of the tensions associated with democratic engagement: asset-oriented norms and co-creation (as they occur within the Interactive
Resource Center, described below by Kathleen) and place-based partnerships and a process orientation toward impact (as they occur within ioby, described below by Brandon). We offer these examples not as success stories full of lessons learned and words of wisdom but rather as demonstrations of both challenges and possibilities - attempting in this way to shine light on the complexities of democratic engagement as experienced in communities.

\section{Interactive Resource Center}

The Interactive Resource Center (IRC, http:// gsodaycenter.org/) in Greensboro, North Carolina, is a daytime center for people experiencing homelessness. The IRC's mission is to "assist people who are homeless, recently homeless, or facing homelessness [in reconnecting] with their own lives and with the community at large." We offer practical services: laundry, showers, access to computers and Internet, case management, and referrals. We also partner with other nonprofits and grassroots organizations, sharing our space as an incubator for multiple services and activities (e.g., medical services, art therapy, gardening, transportation via refurbished bicycles, GED courses, and weekly community vegetarian dinners). The following analysis of the IRC's efforts to enact an asset-based orientation and co-creation is based on a snapshot of the organization from 2010-2014, a period that most honestly reflects the aspirations relevant to this thought piece.

At its inception, the people designing the IRC many of whom were experiencing homelessness at the time - intentionally adopted an asset orientation: peer-based, strengths-focused, and collaborative. As we say every day in our morning meeting: "This is the Interactive Resource Center. Your best resource is each other." Our intention is for every- 
one affiliated with the organization to experience it as their community. The term "guest" displaces the term "client" - the common social service agency name for a person accessing services - because we believe it better establishes a respectful space and affirms non-hierarchical, multi-directional relationships. Guests' artwork hangs on the walls. Guests sweep the floors, take out the trash, and donate money for coffee. Former guests volunteer on weekends. Staff sit in the dayroom to catch up with people they have not seen in awhile. When everyone is viewed as having valuable knowledge and skills to contribute to the organization and to each other, artificial lines that can otherwise divide people begin to blur and the IRC transforms from an organization to a community.

Even with all of these investments in being assetbased, however, there are still challenges associated with the status quo understanding of homelessness (i.e., as the result of individuals' poor decisions). This is reflected in the ways some volunteers view guests from a deficit perspective: assuming individuals who frequent the IRC do not possess the skills, knowledge, or attitudes to be successful and must be "helped" by those who do have such attributes. Some staff push strongly for "accountability" among the guests, proposing, for example, that people should not be allowed to simply sit in the dayroom but rather should be expected to participate in job skills or computer training courses. Even guests sometimes try to make sure others (staff, volunteers, local community members) understand that they themselves are not "that type of homeless person" - meaning one who doesn't work hard, may use drugs or alcohol, may have an unmanaged mental illness, or doesn't really want to change or be a "contributing member of society." These attitudes clash with our commitment to being asset-based, creating disagreements among guests, staff, and volunteers. At the same time, these moments of friction give us opportunities to disrupt status quo assumptions, to educate ourselves and others, and to highlight the gifts that all IRC guests, staff, and volunteers bring to our community.

The IRC's commitment to co-creation is enacted in various ways: working toward transparency within organizational practices (e.g., guests participate in the hiring process for all new staff), creating space for discussion and shared decision-making amongst all IRC community members (e.g., changes in policies and practices are always brought to the morning meeting for discussion), and valuing and seeking out the knowledge of individuals based on their lived experiences (e.g., the floor plan for our new building was created with significant input by people experiencing homelessness because they knew best what to incorporate into the design of the building). As a result of these practices, which have been unfamiliar and even uncomfortable at times, there exists a "co-" ethos within the IRC. For people who have been part of the IRC for a while, "coness" is part of the culture: guests and volunteers know - and expect - they will be a part of decisionmaking and project development. Certain projects (e.g., storyscapes) and programs (e.g., the garden) were co-constructed by guests and volunteers, not initiated by staff, and a collaborative ethos persists through changes in their structure and membership.

There are numerous challenges to enacting cocreation, layered with issues of power, expectations, time, growth, and transiency of guests and volunteers. A stark shift in "co-" practices occurred when the IRC moved to its current location, nearer to downtown. Attendance exploded, from 75 guests on a busy day to 150 guests on a slow day. Several barriers to co-ness developed: the staff - which did not increase - quickly became overworked, more crisis situations emerged (e.g., need for emergency housing), and guests became more transient, sometimes present daily and at other times only once every six months. Since crisis situations rarely allow time for shared decision-making, staff found themselves making decisions independent of guest or volunteer input. This shift in operations had numerous effects: guests and volunteers feeling less engaged with what we thought of as our organization - including perceived lack of transparency and thus less trust in decisions - and staff feeling frustrated because of the increased number and pace of decisions to be made without time to discuss ideas with others. Very quickly there was a breakdown in "co-" practices, which led to disengagement and feelings of powerlessness. We haven't resolved all of these issues, but special interest groups have emerged within which co-creation is easier to implement: a creative writing group, the Artifacts Art Cooperative, the Greensboro Voice quarterly newspaper, and the Tiny Houses initiative (see Hicks, Seymour, \& Puppo, 2015 for a discussion of corelationships in Tiny Houses Greensboro). In these smaller groups, people share leadership roles and decision-making, and projects are redefined with the ebb and flow of people.

These tensions around being asset-based and cocreative always exist at the IRC, even as we gain more understanding of each other, in part because our community is always in transition. There are never two days alike at the IRC, including who is there volunteering or seeking services, which means we need to revisit these fundamental ideas regularly in morning meetings, staff meetings, and volunteer orientations. Trying to live them out 
means committing to a process that never ends: we are asset-oriented and co-creative and can always also be more deeply both of these.

\section{ioby}

ioby (www.ioby.org) is an online crowdresourcing platform headquartered in Brooklyn, $\mathrm{NY}$, and powered by a national network of leaders, donors, and volunteers who support citizen-led, neighbor-funded initiatives in urban areas around the United States. ioby's mission is to strengthen neighborhoods by supporting local leaders who want to make positive change through engaging their neighbors, one block at a time; We believe such individuals are among the most important assets in every community. The organization's name is derived from "in our backyards," the positive opposite of the disparaging acronym NIMBY ("not in my backyard"). Projects range from community gardens and neighborhood composting systems, to bike lanes and crosswalks, to tool-sharing libraries and small-scale solar power systems - with an average budget of about $\$ 4000$ and an average donation of about $\$ 75$. As of 2016 , ioby has supported the leaders behind more than 675 projects who have raised almost $\$ 2.5$ million through crowd-resourcing. Crowd-resourcing combines the concepts of crowd-funding (the ability to pool small donations made online to a specific cause or project) and resource organizing (a core tenet of community organizing that considers activists and advocates the best supporters to ensure success of a cause or project). It gives anyone and everyone the ability to organize all kinds of capital - cash, social capital, in kind donations, volunteer time, advocacy - from within the community to serve the community. Two interrelated dimensions of ioby's work - our place-based focus on projects in communities across the country and our commitment to impact that values process as much as product - are simultaneously strengths and sources of tension.

Place is central to ioby's work. It grounds the kinds of projects we support and gives rise to the community energy behind them. Every one of our projects is based in a neighborhood somewhere: that says it all. One of ioby's five core principles is that "local is best" - that "neighbors know best what their neighborhoods need . . . are best equipped to innovate, organize, and make positive change . . . are the best long-term stewards of solutions." Another is that "small is big" - that "small, neighborhood-scale actions have far-reaching and long-lasting impact on places and on people's lives ... [and] taken together ... make up a powerful movement of neighbor-led positive change that inspires hope and benefits us all." The grounding in place embodied by these principles reminds us that every interaction with citizen-leaders and their neighbors is significant. Place also provides a common language through which local leaders relate to one another across diverse project types, unique geographies, and particular challenges. And it has guided our growth into a national organization that supports citizen-led change in over 150 cities across the U.S. We have a physical presence in an everincreasing number of cities - New York City, Memphis, Cleveland, Detroit, and Pittsburgh - where we hire local staff to work on the ground rather than remotely from our headquarters. This model helps build place-based partnerships and trust.

The tension here involves being place-based ... everywhere. ioby is at once distributed and centralized, locally invested and outsider. Except in the aforementioned cities where we partner with respected local organizations and hire staff with deep community experience, we operate primarily out of the single city where we first developed our placebased model: New York City. We have deliberately expanded our connections with local leaders well beyond that community, however, because we believe that a national network of such leaders (with their donors and volunteers), each grounded in local work, can leverage collective resources, successes, challenges, diverse expertise, and varied passions and thus have a unique and powerful voice on the national stage. But scaling our organization to serve any leader, in any neighborhood, anywhere in the country means we cannot be present ourselves on the ground alongside them as that would take hundreds more staff than we will likely ever have. Further, because we are a national organization, we can easily come across as an outsider - perhaps worse, one from New York City - to potential local partners. Our team must confront our own outsider status when working with leaders by phone and email from our Brooklyn office and during visits to neighborhood project sites. We think about our work not in the dichotomous terms of local and national, but rather as a system that links the two - indeed, sees them as powerfully interdependent - through a network of relationships. However, this conceptual frame is constantly put to a practical test during conversations we have with individual leaders about local history, challenges, and opportunities - around which, no matter how well intentioned, our national office staff simply will never be able to interact with our leaders as a local resident might.

As with most nonprofits, ioby exists to make an impact - in our case, on the leaders we serve and their communities. We think about change agency in a way that is at once very concrete (the proj- 
ects) and very diffuse (the networks), challenging the usual notions of innovation and change coming only from centralized "top-down" structures and focusing instead on distributed, grassroots, "bottom-up" approaches. Central to our approach are two convictions about change: (a) we believe local leaders bringing local ideas to life via relationships within and investment from the community is an effective way to support communities in reimagining what is possible, and (b) we believe building capacities of local leaders and organizations to marshal resources is effective as both shortterm strategy and long-term investment. We use a coaching approach to training in crowd-resourcing as a method of fundraising, drawing from leading grassroots fundraising collaboratives and integrating the successful practices and techniques of the leaders in our network. We learn from them and assemble and share with others their knowledge on a wide variety of technical, tactical, and subject matter-specific issues - essentially, crowdsourcing the expertise we share. In some ways, then, the product of our work - in the form of successfully executed community projects, which we value highly - is less central to our conceptualization of the change we pursue than is the process by which it happens. Our way of thinking about impact is as much process- as product-oriented. For us, impact is about providing timely, right-sized capacity building around resource generation and organizing to leaders who are poised to catalyze change in their communities.

A key challenge in this take on impact is that few funders and investors support it (whether foundations, individuals, or agencies). For many, our focus on process is too slow, too uncertain, too diffuse, or too hard to measure. These are fair critiques on some level that represent very real challenges as we build our own capacity to pursue our mission in a world focused on quick wins, return on investment, and other product-oriented metrics. The onus is on us not only to meet these criticisms with thoughtful responses, but also to mount our own efforts to "prove" that our process-oriented approach provides effective and efficient solutions in the short term. This often puts us in the position of focusing simultaneously on the short game and the long game, and it is difficult not to allow one to overwhelm the other. The full impact of building social capital and increasing neighborhood involvement in civic work is notoriously difficult to measure and often takes time to manifest. So we often succumb to citing impacts such as number of trees planted, miles of bike lanes added, or number of children engaged in a project as short-term, product-based measures. In doing so, we run the risk of conflat- ing - indeed, displacing - process-oriented values and impacts with product-oriented values and impacts, which can undermine the fundamental conversations and models of change we are trying to catalyze.

We do not expect these tensions around being place-based and process-oriented in our conception of impact to be resolved, but we do find that a systems perspective helps us understand them and hold them more creatively than we otherwise might. As we grow a national network of local citizen-leaders, we try to think of the unique characteristics that comprise their local contexts as a series of overlapping systems that contribute to the adaptability and resilience of the network overall and the social fabric of the U.S. more generally. These multiple systems interact to generate continuously emerging opportunities for connection, learning, and new understandings across the various local contexts. Similarly, we try to maintain a systems orientation to impact: not viewing it as a choice between process and product or short-term and long-term but considering all of these important dimensions simultaneously and in light of each other and trying to integrate them to generate synergistic alternatives.

\section{More Community Stories Please}

As we have surfaced in these two stories - likely no surprise to readers - democratic engagement is hard. Really hard. Individuals and organizations often face very real challenges in their efforts to enact democratic engagement, as illustrated here with four leading tensions: (a) adopting an asset-based orientation in a culture that tends to focus on needs and problems, (b) positioning everyone involved as co-creators despite deeply enshrined hierarchy, (c) engaging with the contexts of local places in work that is also of necessity and by design caught up in large scale (e.g., national) structures, and (d) valuing the dynamics of empowering processes in the face of pressures to focus almost exclusively on products. For the five of us as practitioner-scholars, it is just such tensions - more than contested purposes - that make SLCE so difficult to undertake effectively and with integrity, both on campuses and in communities.

A key takeaway here is that higher education is not and need not always be involved in, much less at the forefront of, community engagement work. Indeed, partnership with higher education institutions often exacerbates some of the tensions we have discussed here, especially when faculty, staff, and students bring a sense of themselves as experts relative to community members. As one example of the added challenge, ioby finds the tensions around 
conceptualizing impact in terms of process further intensified insofar as partnerships that involve the academy often require a distinct focus on learning outcomes and products. As one example of a response to the tensions of co-creation, a volunteer coordinator at the IRC engages with them directly by sharing with her academic partners a chapter written by community partner Amy Mondloch (2009) that speaks to the challenges and possibilities of positioning everyone involved in SLCE as "learners, teachers, and leaders" (p. 146).

All participants in SLCE - perhaps especially our colleagues in the academy - need to take seriously the experience of community members and organizations who have learned to navigate the tensions of democratic engagement. Ask them if you can visit and watch their day-to-day operations. Incorporate these two and other such stories into faculty and staff development activities. Insist that SLCE events on campus include community partners not merely as guests but as educators; and explicitly position yourself, whether student, faculty, or staff, as a learner in that setting. Invite community members not only to celebrate accomplishments but also to bring a critical perspective to their own and your work. Create ways to think and plan and write together; and please share what you learn with the rest of us!

Why do we believe so strongly that the SLCE movement must learn from the democratic engagement work of community members and organizations? When we look at examples of SLCE projects and partnerships, we see ourselves and others trying to live out deeply held commitments to reciprocity, power sharing, and sustainable and systemic change in contrary contexts of individualism, competition, and short-term reactivity. More generally, we see ourselves and others trying to be co-educators, co-learners, and co-generators of knowledge and practice while encountering deeply enshrined resistance in our society, our organizations, and ourselves. The result is often a discouraging disconnect between what we want to be and do and what we actually are and do - across all partner categories, roles, and identities in SLCE. We all can find encouragement and guidance in self-critical stories of on-the-ground efforts, happening day to day in communities, of persistence and resilience in the face of the very norms SLCE seeks to disrupt and replace with more hopeful and empowering alternatives. We believe the two examples shared here merely scratch the surface of an incredibly rich tapestry of democratic engagement work being done in civil society by non-higher education institutions. We invite our SLCE colleagues, on campuses and especially in communities, to in- quire into and share your own such stories.

\section{References}

Hicks, T., Seymour, L., \& Puppo, A. (2015). Democratic relationships in service-learning: Moving beyond traditional faculty, student, and community partner roles. Michigan Journal of Community Service Learning, 22(1), 105-108.

Interactive Resource Center. (n.d.). Retrieved from www. gsodaycenter.org

ioby. (n.d.). Retrieved from www.ioby.org

Mondloch, A. (2009). One director's voice. In R. Stoecker \& E. Tryon (Eds.), The unheard voices: Community organizations and service learning (pp. 136-146). Philadelphia: Temple University Press.

Zlotkowski, E. (2015). Twenty years and counting: A framing essay. Michigan Journal of Community Service Learning, 22(1), 82-85.

\section{Authors}

BRANDON WHITNEY (brandon@ioby.org) lives in Brooklyn, New York, and is cofounder \& $\mathrm{COO}$ of ioby.org, a crowd-resourcing platform powered by a national network of leaders, donors, and volunteers that support citizen-led, neighborfunded initiatives in urban areas. He is an accidental techie interested in how blending technology and civic life can help us build healthier neighborhoods, more just communities, and more sustainable cities. An environmental anthropologist by training, Brandon is also an amateur chef, fair-weather runner, and urban gardener.

STACEY MUSE (staceymuse@gmail.com) is a doctoral candidate in the Higher Education program at the University of Denver. Having worked in the nonprofit sector for over a decade and holding an MA in nonprofit management, she is interested in the community voice/perspective and outcomes of community-university partnerships. She currently leads the Office of Service-Learning and Civic Engagement at the University of Nevada, Reno. When she's not working on her dissertation, Stacey enjoys sharing her love of music and "dancing" with her 1-year old daughter, laughing with her husband, and cuddling with her dog.

BARBARA HARRISON (barbara.a.harrison@ gmail.com) is a community-based practitionerscholar currently engaged in projects with NGOs responding to the refugee crisis in Greece. She was previously a research associate with the Community Engaged Scholarship Institute/Research Shop at the University of Guelph and a campus leader in an institution-wide service-learning initiative at Brock University, both in Ontario, Canada. Barbara 
is an avid vegetable gardener who has a great love of dogs and their shenanigans.

KATHLEEN E. EDWARDS (kathleen.e.edwards@gmail.com) volunteered at the Interactive Resource Center starting in 2010 and then accepted a full-time program director position from 2014-2016. Now she is focused on writing her dissertation, which challenges U.S.-based status quo frameworks for addressing homelessness. Additionally, she works part-time in the Institute for Community and Economic Engagement at the University of North Carolina at Greensboro where her multiple years of experience with both community and campus partner roles serve her well in supporting SLCE partnerships. Kathleen keeps a growing list of what she will do with her free time once she has finished her dissertation.
PATTI H. CLAYTON (patti.clayton@curricular engagement.com) is an independent consultant and SLCE practitioner-scholar (PHC Ventures) as well as a senior scholar with IUPUI and UNCG. Increasingly seeing democratic community engagement as co-inquiry among all partners, her current interests include critical reflection for civic learning; the integration of SLCE and relationships within the more-than-human world; and the power of such "little words" as in, for, with, and of to shape identities and ways of being with one another in SLCE. Not known for brevity, Patti is enjoying learning to co-author short essays and even blog posts with friends and colleagues old and new. 